\title{
HOW CONFLICTS MAY IMPACT INTENTIONS TO SHARE KNOWLEDGE IN A VIRTUAL TEAM
}

\author{
Linwu Gu, Indiana University of Pennsylvania,lgu@iup.edu \\ Jianfeng Wang, Indiana University of Pennsylvania, jwang@iup.edu
}

\begin{abstract}
Knowledge Sharing is very important to achieve productive teamwork, and virtual teams become more and more common in organizations. Although the research of knowledge sharing has been discussed a lot and the relationship between conflicts and performance are explored in previous studies, there has been little research on the impacts of conflicts on intentions to share knowledge. We construct a theoretical model to examine the relationships between the attitude toward knowledge sharing and conflicts, and to finally investigate the intentions of knowledge sharing in a virtual team. A survey was conducted to collect data to show that the team conflicts decrease when the attitude toward knowledge sharing increases.
\end{abstract}

Key Words: Knowledge Sharing, Task Conflicts, Interpersonal Conflicts and Virtual Team

\section{INTRODUCTION}

In the studies of Jehn [14] and Pelled [20], the conflicts are distinguished between interpersonal conflicts and task conflicts. Task conflicts are defined as different perspectives relating to team tasks. Interpersonal conflicts are defined as disagreement among team members [23], and involve personal issues such as mutual dislike among team members. A recent meta-analysis (Pelled et al. 1999) suggests that both task and interpersonal conflicts are consistently linked with worse performance, and can negatively affect performance and satisfaction of an organization [15]. Hinds and Mortensen [11] note "little work has yet examined different dimensions of distributed work and how these dimensions shape dynamics". Interestingly, a relationship between conflicts and shared identity and shared context within teams was reported [11] in the development of a shared context.

A knowledge-based view of a company plays an important role in explaining the sustainable competitiveness of a firm [13]. Similarly, the knowledge-based view of a virtual team assumes that the knowledge provides an opportunity for sustainable competiveness. Knowledge sharing process is defined as "exchange of knowledge between at least two parties in a reciprocal process allowing reshaping and sense-making of the knowledge in the new context" [27]. However, organizations often face difficulties when trying to encourage knowledge-sharing behaviors. This raises the issue of how organizations can effectively encourage individual knowledge-sharing behavior [2]. Cummings [4] finds that both intragroup and external knowledge sharing have significant effects on group performance, and external knowledge sharing was more strongly associated with performance when work groups are more structurally diverse. O'Leary and Cummings [18] provide a framework of how to conceptualize the spatial, temporal and configurational characteristics of geographic dispersion in teams. Siebdrat et al. [24] find that "virtual teams can outperform their collocated counterparts when they are set up and managed in the right way". They suggest that participants of virtual team need to use socio-emotional and task-related skills such that virtual teams can incorporate dispersed knowledge effectively.

By taking a closer look at team conflicts and the attitude toward knowledge sharing, it can be seen that there is a relationship between knowledge sharing attitudes and team conflicts, which finally affect intentions to share knowledge. Summarily, task and interpersonal conflicts should be explored in a knowledge sharing study where, we want to examine conflicts and to study whether knowledge sharing is both constrained and difficult with existing conflicts in virtual team for doing so. In this study, we study difficulties of task and interpersonal conflicts on the attitude toward knowledge sharing in virtual teams before launching knowledge-sharing intentions. 


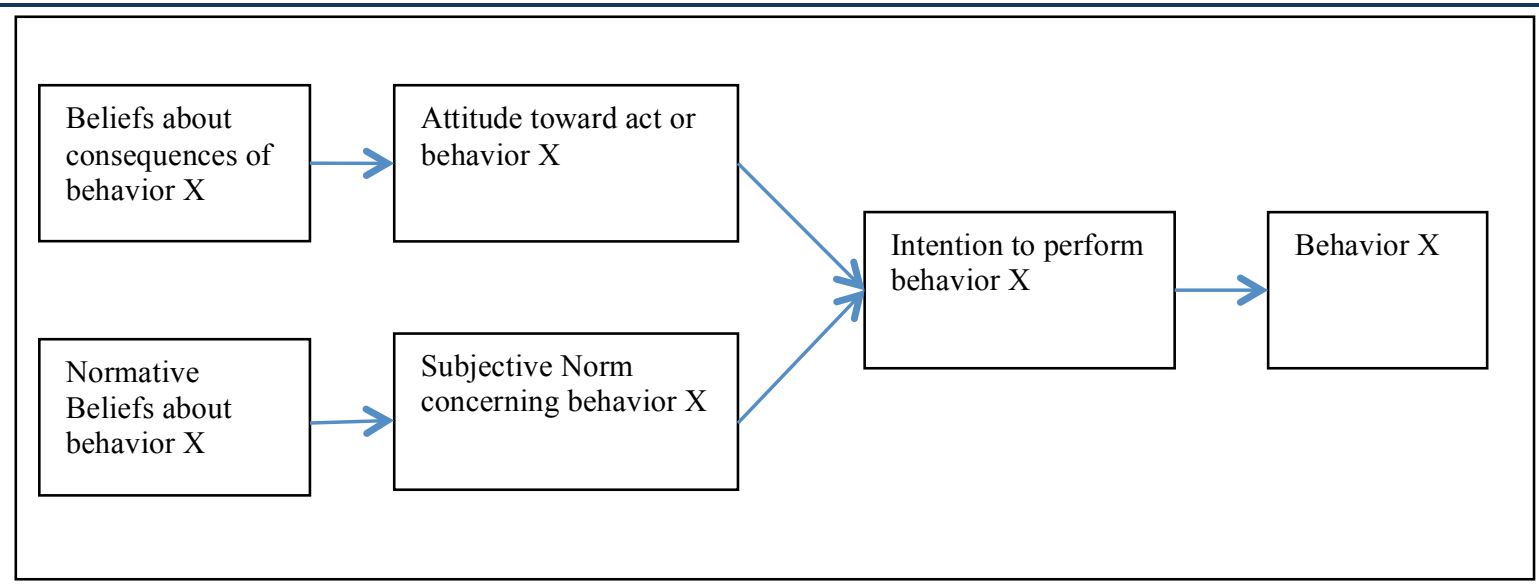

Figure-1: Social cognitive theory model (TRA) (Fishbein and Ajzen, 1975)

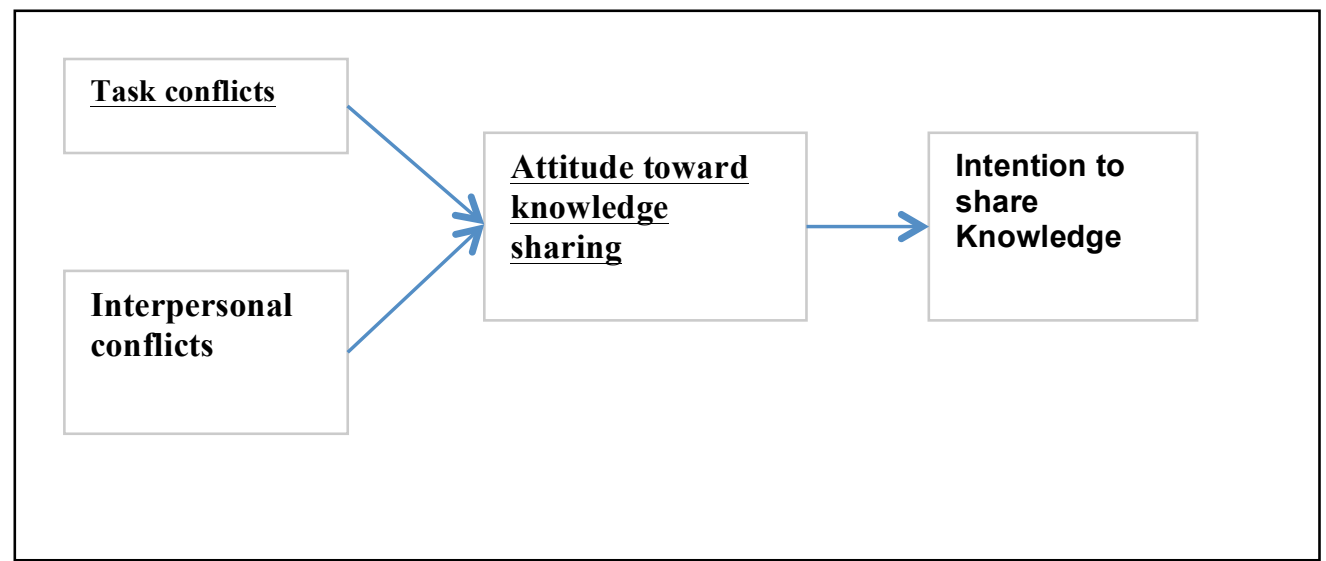

Figure-2: Research model of conflicts and knowledge sharing intention

\section{THEORY FOUNDATION, MODELS AND HYPOTHESES}

In the theory of Reasoned Action (TRA) [6] (Figure 1), one of variables in TRA is the attitude toward the behavior, and it is defined as the individual's positive or negative feelings about performing a behavior. Another variable is belief that can refer to viewpoints, perspectives, and agreements. TRA explicitly describes the mechanisms through which beliefs influence behavior, and it proposes that the intentional behavior is impacted by attitudes. As demonstrated by Hinds and Bailey [10], conflict is hard to manage in distributed teams, and virtual teams were shown to experience conflicts due to the distance that separates team members [10, 16, 22]. Moreover, in the recent meta-analysis of De Dreu \& Weingart [5], both task and interpersonal conflicts are consistently linked with worse consequences, particularly when teams are engaged in highly complex tasks. Task conflicts indicate different perspectives, unshared information, and pressures in distributed teams $[1,3,10]$, while interpersonal conflicts reflect the anxiety, hostility, and time and energy consumption associated with emotional disagreements $[20,15]$.

Knowledge has long been recognized as a valuable resource for organizational growth and sustained competitive advantage [8]. Knowledge is valuable, and sharing it increases team activities [2]. The sharing could be done directly via communication or indirectly via some knowledge archive of competitive advantage. In fact, it is noted in the literature that sharing of mutual knowledge is a fundamental issue for virtual team performance and development [3].

An individual's attitude toward knowledge sharing is driven primarily by anticipated reciprocal relationships regarding knowledge sharing [2]. However there are obstacles to knowledge sharing. Knowledge sharing is both 


\section{Issues in Information Systems \\ Volume 14, Issue 2, pp.79-86, 2013}

constrained and difficult without proper and necessary incentives in the absence of coercion or appropriable encouragements with group task. Individuals will tend to withhold knowledge. Some teams are behind schedule, and do not always work as intended due to problems with team confliction, especially when tasks are large and globally distributed [9].

Therefore, it is important to understand a team's ability to coordinate through team knowledge about the task and about team members. Low levels of conflicts between the teams are considered essential for effective communication to improve the quality of discussion between teams and to facilitate knowledge sharing. When team members use more organization-wide information and knowledge, there are fewer conflicts that arise from perceived interpersonal incompatibilities and clashing personalities. In addition, using existing knowledge might eliminate debates regarding the task being performed, and might typically remove the intense negative feelings characteristic of interpersonal conflict. Therefore, we propose our research hypotheses as following:

$\mathrm{H}_{1}$ : Task conflicts decrease the attitude toward knowledge sharing.

$\mathrm{H}_{2}$ : Interpersonal conflicts decrease the attitude toward knowledge sharing.

$\mathrm{H}_{3}$ : The attitude toward knowledge sharing positively affects intentions to share knowledge.

$\mathrm{H}_{4}$ : The attitude toward knowledge sharing mediates between task conflicts and intentions to share knowledge.

H5: The attitude toward knowledge sharing mediates between interpersonal conflicts and intentions to share knowledge.

\section{RESEARCH METHODOLOGY AND ANALYSIS}

\section{SUBJECT, TASK, AND PROCEDURES}

The total subjects are 116. They are junior or senior college students from a large university located northeast of the USA. The subjects were assigned randomly to 28 groups for their semester projects in their online classes. 25 groups had 4 group members, 2 groups had 5 group members, and 1 group had 6 group members. Each member of a group came from the same class, however, they were assigned by the last four digits of their student ID and they discussed their projects. Group members did not meet with each other at any physical location. All their communications were done through a group discussion bulletin available and set up through WebCT. Different groups have different tasks in the same class, and group project topics were assigned randomly.

One group was only assigned with one project. Finally team members individually completed a post session questionnaire after finishing their projects.

\section{VARIABLES}

The attitude toward knowledge sharing and knowledge sharing intentions are measured using Bock et al. [2]. Interpersonal conflicts and task conflicts are measured using Hinds \& Mortenson [10]. 
Table-1: Convergent Validity Test

\begin{tabular}{|c|c|c|}
\hline Constructs & $\begin{array}{c}\text { Average } \\
\text { variance }\end{array}$ & $\begin{array}{c}\text { Composite } \\
\text { reliability }\end{array}$ \\
\hline Task conflicts & 0.61 & 0.821 \\
Interpersonal conflicts & 0.69 & 0.706 \\
Attitude toward knowledge & 0.58 & 0.814 \\
Intentions to share knowledge & 0.71 & 0.732 \\
\hline
\end{tabular}

Table-2: Discriminant Validity

\begin{tabular}{|c|c|c|c|c|}
\hline & Task conflicts & $\begin{array}{c}\text { Interpersonal } \\
\text { conflicts }\end{array}$ & $\begin{array}{c}\text { Attitude toward } \\
\text { knowledge }\end{array}$ & $\begin{array}{c}\text { Intentions to share } \\
\text { knowledge }\end{array}$ \\
\hline Task conflicts & 0.781 & & & \\
\hline $\begin{array}{c}\text { Interpersonal } \\
\text { conflicts }\end{array}$ & 0.437 & 0.831 & 0.762 & \\
\hline $\begin{array}{c}\text { Attitude toward } \\
\text { knowledge }\end{array}$ & 0.621 & 0.542 & 0.461 & 0.843 \\
\hline $\begin{array}{c}\text { Intentions to share } \\
\text { knowledge }\end{array}$ & 0.390 & 0.212 & & \\
\hline
\end{tabular}

Table 3: Hypothesis Testing Results

\begin{tabular}{|c|c|c|c|c|}
\hline Hypotheses & Relationship & $\boldsymbol{\beta}$ & $\begin{array}{c}\text { P- } \\
\text { value }\end{array}$ & Testing Outcome \\
\hline $\mathrm{H}_{1}$ & $\begin{array}{c}\text { Task conflicts-> Attitude toward } \\
\text { knowledge sharing }\end{array}$ & -0.37 & 0.549 & Not supported \\
\hline $\mathrm{H}_{2}$ & $\begin{array}{c}\text { Interpersonal conflicts -> Attitude toward } \\
\text { knowledge sharing }\end{array}$ & -0.14 & 0.000 & Supported \\
\hline $\mathrm{H}_{3}$ & $\begin{array}{c}\text { Attitude toward knowledge sharing -> } \\
\text { knowledge sharing intention }\end{array}$ & 0.52 & 0.031 & Supported \\
\hline $\mathrm{H}_{4}$ & $\begin{array}{c}\text { task conflicts -> Attitude toward will be } \\
\text { fully mediated by knowledge sharing }\end{array}$ & -0.15 & 0.002 & $\begin{array}{c}\text { Not Supported } \\
\text { The relationship between task } \\
\text { conflicts (Independent Variable) } \\
\text { and attitude toward knowledge } \\
\text { sharing (Mediator) is not } \\
\text { significant. }\end{array}$ \\
\hline $\mathrm{H}_{5}$ & $\begin{array}{c}\text { Interpersonal conflicts -> Attitude toward } \\
\text { will be fully mediated by knowledge } \\
\text { sharing }\end{array}$ & 0.68 & 0.026 & \begin{tabular}{c} 
Supported \\
\hline
\end{tabular} \\
\hline
\end{tabular}

\section{Measurement Model}

Confirmatory factor analysis is used to test the measurement model for the reliability and the validity and to check whether the factor model is valid. The results of confirmatory factor analysis confirm both convergent and discriminant validity (Table 1 and 2). Convergent validity is evaluated based on composite reliabilities and average variances extracted. From Table 1 , the average variances extracted from constructs all exceed 0.5 , and the composite reliability are all greater than 0.7 . 
To assess discriminant validity, the square root of the average variance extracted is compared to the correlations of each pair of constructs. Discriminant validity is proved when the square root of the average variance extracted is greater than the corresponding constructs correlation (Table 2).

\section{STRUCTURAL MODEL ANALYSIS}

Structural model was assessed by conducting a path analysis using LISREL. We ran three separate structural equations to examine significant relationships between our independent and mediating variables, and those between our mediating and dependent variables. The independent variables should be tested how they are related to the dependent variables when the mediator is not tested, and that the relationship is reduced when the mediator is added to the structural model.

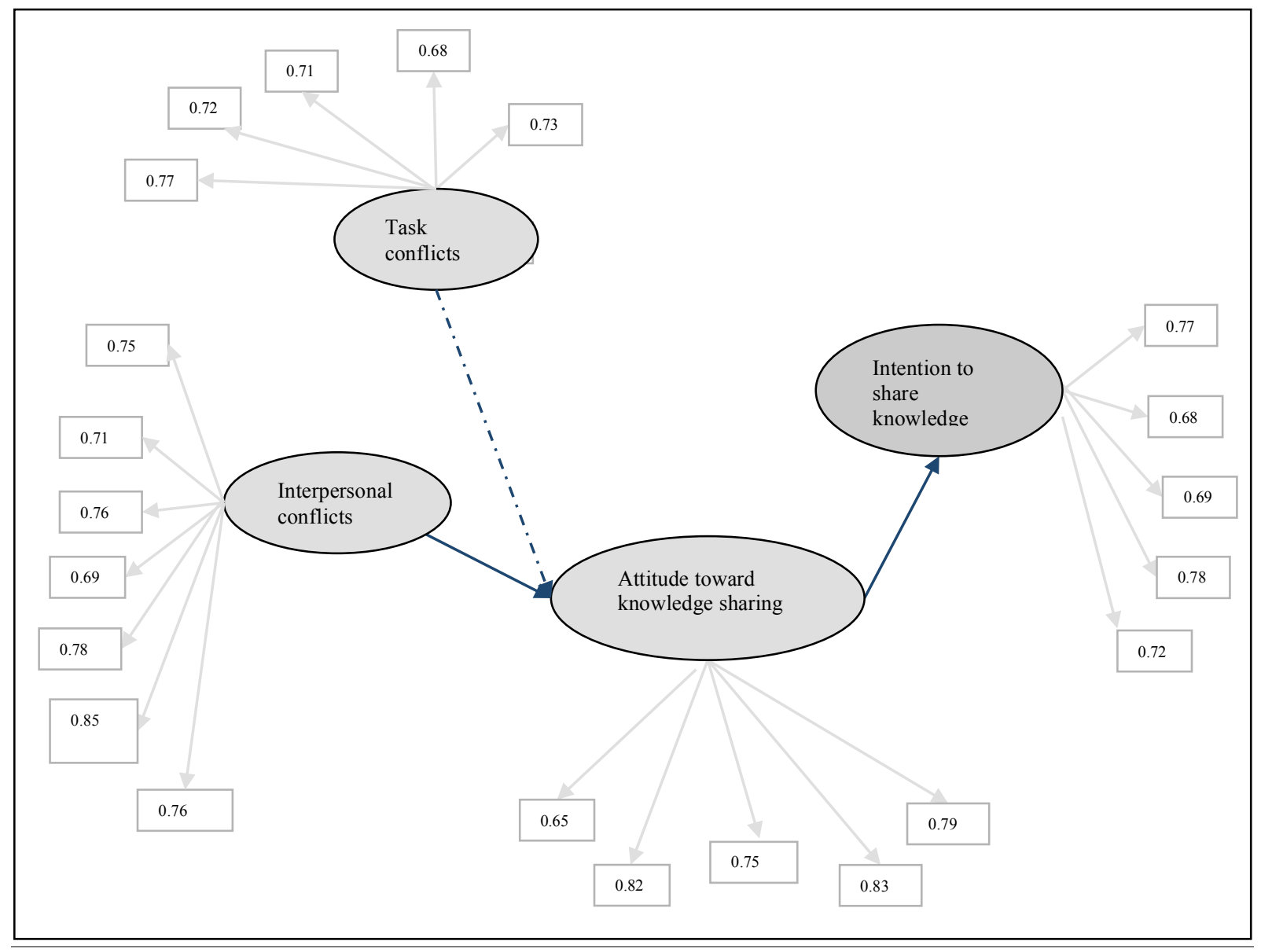

Figure-3: Path diagram with the standardized results of the effects of conflicts and attitude toward knowledge sharing on knowledge sharing intentions 


\title{
Issues in Information Systems
}

Volume 14, Issue 2, pp.79-86, 2013

\begin{abstract}
RESULTS
The path diagram shows the relationship of conflicts, the attitude toward knowledge sharing, and intentions to share knowledge (Figure 3). Results of the hypothesis testing are summarized in Table 3. No significant relationship is found between task conflicts and the attitude toward knowledge sharing; therefore, $\mathrm{H} 1$ and $\mathrm{H} 4$ are not supported.

The attitude toward knowledge sharing has positive significant effects on the intentions to share knowledge. The negative significant relationship between interpersonal conflicts and the attitude toward knowledge sharing was found (Table 3). Therefore, $\mathrm{H} 2$ and $\mathrm{H} 3$ are supported. Additionally, the mediating effect of attitude toward knowledge sharing between interpersonal conflicts and knowledge sharing intention is identified significantly, because the relationship between interpersonal conflicts and knowledge sharing was reduced when the mediator, attitude toward knowledge sharing was added into the model, so H5 is supported.
\end{abstract}

\section{CONCLUSIONS}

The theoretical contribution of this study is the relationships between knowledge processes and team conflicts in a virtual team. Based on prior research on conflicts, we categorize conflicts in virtual teams into two types: interpersonal conflicts and task conflicts. We empirically validated how the task conflicts and interpersonal conflicts may affect intention to share knowledge.

The virtual teams in this study are student semester project groups using D2L discussion tools, emails, and other virtual communication tools. A future research should use employees of organizations involved in virtual teams.

\section{APPENDIX A}

\section{Task Conflict [10]}

a) Please answer the following questions about the extent to which differences in opinion and disagreements occur within the TEAM.

b) How frequently are there conflicts about ideas in the TEAM?

c) How much conflict about the work you do is there in the TEAM?

d) How often do people in the TEAM disagree about opinions regarding the work being done?

e) To what extent are there differences of opinion in the TEAM?

\section{Interpersonal Conflict [10]}

a) Please answer the following questions about the extent to which differences in opinion and disagreements occur within the TEAM.

b) How much friction is there among members in the TEAM?

c) How much are personality conflicts evident in the TEAM?

d) How much tension is there among members in the TEAM?

e) How much emotional conflict is there among members in the TEAM?

f) To what extent do people take the arguments in the TEAM personally?

g) How much jealousy or rivalry is there among the members in the TEAM?

\section{Attitude toward knowledge sharing [2]}

a) My knowledge sharing with other organizational members is good

b) My knowledge sharing with other members is harmful

c) My knowledge sharing with other members is an enjoyable experience

d) My knowledge sharing with other organizational members is an enjoyable experience.

e) My knowledge sharing with other members is a wise move

\section{Intention to Share Knowledge [2]}




\section{Issues in Information Systems \\ Volume 14, Issue 2, pp.79-86, 2013}
a) I will share my work reports and official documents with members of my organization more frequently in the futures
b) I will always provide my manuals, methodologies and models for members of my organization
c) I intend to share my experience or know - how from work with other organizational members more frequently in the future
d) I will always provide my know -where or know- whom at the request of other organizational members
e) I will try to share my expertise from my education or training with other organizational members in a more effective way.

\section{REFERENCES}

1. Armstrong, D. J. and P. Cole. (2002). Managing distances and differences in geographically distributed work groups. P. J. Hinds, S. Kiesler, eds. Distributed Work. MIT Press, Cambridge, MA, pp. 167-186.

2. Bock, G.W., Zmud, R.W. Kim, Y. G, \& Lee, J.N. (2005). Behavioral intention formation in knowledge sharing: examining the roles of extrinsic motivators, Social-Psychological Forces, and Organizational Climate, MIS Quarterly, 29 (1), 87-111.

3. Cramton, C. D. (2001). The mutual knowledge problem and its consequences for dispersed collaboration, Organization Science, 12(3), 346-371.

4. Cummings, j.N., (2004) Work Groups, Structural Diversity and Knowledge Sharing in a Global Organization. Management Science, 50(3), 352-364.

5. De Dreu, C. K. W., \& Weingart, L. R. (2003). Task versus relationship conflict and team effectiveness: A metaanalysis. Journal of Applied. Psychology, 88(4), 741-749.

6. Fishben, M., \& Ajzen, I. (1975). Belief, attitude, Intention, and Behavior: An introduction to Theory and Research, Reading, MA: Addison-Wesley.

7. Siebdrat, F., Hoegl, M., and Ernst, H. How to Manage Virtual Teams, Sloan Management Review, summer 2009, 50(4) 63-68.

8. Grant, R. (1996). Toward a knowledge-based theory of the firm, Strategic Management Journal, 17(Winter Special Issue), 109-122.

9. Herbsleb, J.D., \& Grinter, R.E. (1999). Architectures, coordination, and distance: Conway's law and beyond. IEEE Software, $16(5), 63-70$.

10. Hinds, P.J., \& Bailey, D.E. (2003). Out of sight, out of sync: understanding conflict in distributed teams, Organization Science, (14)6, 615-632.

11. Hinds,P., \& Mortensen, M. (2005). Understanding conflict in geographically distributed teams. Organization Science, 16(3), 290-307,

12. Higgins, C. (1995). Application of Social Cognitive Theory to Training for Computer Skills, Inform Systems Research, 6(2), 118-143.

13. Itikpen. A., \& Beamish, P. (1997). Knowledge, Bargaining Power, and the instability of international joint ventures. Academy of Management Review, 22(1), 177-202.

14. Jehn, K.A. (1995). A multi-method examination of the benefits and detriments of intragroup conflict. Administrative Science Quarterly, 40, 2 (1995), 256-282.

15. Jehn, K.A. (1997). A qualitative analysis of conflict types and dimensions in organizational groups. Administrative Science Quarterly, 42(3), 530-557.

16. Kraut, R. E., R. S. Fish, \& B. Chalfonte. (1992). Requirements and media choice in collaborative writing. Human Computer Interaction, 7(4), 375-407.

17. Lurey, J.S., \& Raisinghani, M.S. (2001). An empirical study of best practices in virtual teams, Information \& Management, 38(8), 523-544

18. O'Leary M. and Cummings J. The spatial, temporal, and configurational charateristics of geographic dispersion in teams, MIS Quarterly, Sept. 2007, 31(3) 433-452.

19. Pelled, L. H. (1996). Relational demography and perceptions of group conflict and performance: A field investigation. International Journal of Conflict Management, 7(3), 230-246

20. Pelled, L.H, Eisenhardt, K. M., \& Xin, K. R. (1999). Exploring the black box: An analysis of work group diversity conflict and performance. Administrative Science Quarterly. 44(1), 1-28.

21. Pinkley, R.L. (1990). Dimensions of conflict frame: disputant interpretations of conflict. Journal of Applied Psychology, 74 (2), 117-126 


\section{Issues in Information Systems \\ Volume 14, Issue 2, pp.79-86, 2013}

22. Robey, D.L., Smith, L.A., \& Vijayasarathy, L.R. (1993), Perceptions of conflict and success in information systems development projects. Journal of Management of Information Systems, 10(1), 123-139.

23. Robinson, J. P., \& Shaver, P. R. (1973). Measures of Social Psychological Attitudes, Ann Arbor, MI: the Institute for Social Research, University of Michigan.

24. Siebdrat, F., Hoegl, M. and Ernst, H. (2009) How to Manage Virtual teams, MIT SloanManagement Review, 50(4), 63-69.

25. Sonnentag, S. (2000). Excellent performance: the role of communication and cooperation processes, Applied Psychology: An International Review, 49(3), 483-498.

26. Wegner, D. (1986). Transactive memory: a contemporary analysis of group mind, Theories of Group Behavior, $185,185-208$.

27. Willem, A., \& Scarbrough, H. (2002). Structural Effects on Inter-Unit Knowledge Sharing: The Role of Coordination Under Different Knowledge Sharing Needs, the 3rd European Conference On Organizational Knowledge, Learning And Capabilities. Athens, Greece. 